\title{
Respiratory Syncytial Virus Infection as a Precipitant of Thyroid Storm in a Previously Undiagnosed Case of Graves' Disease in a Prepubertal Girl
}

\author{
Ivy R. Aslan, ${ }^{1}$ Elizabeth A. Baca, ${ }^{2}$ R. William Charlton, ${ }^{1}$ and Stephen M. Rosenthal ${ }^{1,3}$ \\ ${ }^{1}$ Division of Endocrinology, Department of Pediatrics, University of California, San Francisco, CA 94143, USA \\ ${ }^{2}$ Department of Pediatrics, Lucile Packard Children's Hospital at Stanford, Palo Alto, CA 94304, USA \\ ${ }^{3}$ Division of Pediatric Endocrinology, University of California, San Francisco, 513 Parnassus Avenue, Suite S-672-D, \\ San Francisco, CA 94143-0434, USA \\ Correspondence should be addressed to Stephen M. Rosenthal, rosenthals@peds.ucsf.edu \\ Received 6 November 2010; Revised 9 January 2011; Accepted 21 February 2011 \\ Academic Editor: Juliane Léger
}

Copyright @ 2011 Ivy R. Aslan et al. This is an open access article distributed under the Creative Commons Attribution License, which permits unrestricted use, distribution, and reproduction in any medium, provided the original work is properly cited.

Graves' disease is less common in prepubertal than pubertal children, and initial presentation with thyroid storm is rare. We report an 11-year-old prepubertal Hispanic girl who presented with a one-day history of respiratory distress, fever, and dysphagia. She had exophthalmos, a diffuse bilateral goiter and was agitated, tachycardic, and hypertensive. Nasal swab was positive for respiratory syncytial virus (RSV). She was diagnosed with thyroid storm and admitted to the pediatric intensive care unit. While infection is a known precipitant of thyroid storm and RSV is a common pediatric infection, to the best of our knowledge, this is the first reported case of RSV infection apparently precipitating thyroid storm in a prepubertal child.

\section{Case Report}

A prepubertal 11-year-old Hispanic girl presented to the emergency department with a one-day history of respiratory distress, fever, and dysphagia that developed after several days of upper respiratory infection symptoms and sore throat.

Her past medical history was notable for prematurity (26 weeks gestational age) associated with chronic lung disease. On exam she was noted to be thin, agitated, drooling, in moderate-to-severe distress, and holding herself in a tripod position. Her temperature was $38.6(\mathrm{C})$ or $101.4(\mathrm{~F})$, heart rate 200 , blood pressure $162 / 93 \mathrm{mmHg}$, respiratory rate 40 , O2 sat $91 \%$ in room air. She had diffuse erythema of the pharynx, exophthalmos and a diffuse bilateral goiter, each lobe measuring $4 \mathrm{~cm} \times 3.5 \mathrm{~cm}$. There were no palpable nodules or tenderness, but a bruit was present. On her lung exam she had bilateral wheezes. She was prepubertal.

Laboratory Tests. Nasal swab Direct Fluorescent Antibody was positive for respiratory syncytial virus (RSV). Table 1 shows thyroid function tests at diagnosis and 1 week after treatment was started (see hospital course).

The patient's chest X-ray showed linear subsegmental densities in both lungs bases as well as prominence of interstitial markings in the lung apices. Multiple cuffed bronchi are seen in the perihilar regions and in the left upper lobe. All these findings are compatible with viral pneumonia.

The following studies were also obtained at baseline: thyroid stimulating immunoglobulin $257 \%$ baseline (normal $<125 \%$ ), anti-thyroperoxidase antibody $4.77 \mathrm{IU} / \mathrm{ml}$ (normal $<0.8$ ), and anti-thyroglobulin antibody $68 \mathrm{IU} / \mathrm{mL}$ (normal $<20$ ).

The patient's score of 60 met criteria for thyroid storm based on Burch and Wartofsky's criteria. A score of 45 or more is highly suggestive of thyroid storm (see Table 2) [1].

Hospital Course. The patient was initially treated with propylthiouracil (PTU), saturated solution of potassium iodide (SSKI), dexamethasone, esmolol infusion, and bronchodilators. She was discharged home on PTU $100 \mathrm{mg}$ PO Q8h, atenolol $50 \mathrm{mg}$ once daily and levalbuterol inhaled. One 
TABLE 1: Laboratory profile from the patient at diagnosis and 1 week posttreatment.

\begin{tabular}{lcc}
\hline Labs (with normal ranges) & At diagnosis & 1 week posttreatment \\
\hline TSH $(0.37-4.42 \mathrm{mIU} / \mathrm{L})$ & 0.01 & - \\
Free T4 $(0.65-1.80 \mathrm{ng} / \mathrm{dl})$ & 8.17 & 1.24 \\
Free T3 $(335-480 \mathrm{pg} / \mathrm{dl})$ & 1918 & 451 \\
\hline
\end{tabular}

TABLE 2: Burch and Wartofsky's criteria for thyroid storm (score of 45 or more is highly suggestive of thyroid storm). The patient's scores are noted in bold.

\begin{tabular}{|c|c|}
\hline \multicolumn{2}{|l|}{ Temperature } \\
\hline $99-99.9$ & 5 \\
\hline $100-100.9$ & 10 \\
\hline $101-101.9$ & 15 \\
\hline $102-102.9$ & 20 \\
\hline $103-103.9$ & 25 \\
\hline$\geq 104$ & 30 \\
\hline \multicolumn{2}{|l|}{ CNS effects } \\
\hline Absent & 0 \\
\hline Mild (agitation) & 10 \\
\hline Moderate (delirium, psychosis, extreme lethargy) & 20 \\
\hline Severe (seizures, coma) & 30 \\
\hline \multicolumn{2}{|l|}{ Gastrointestinal-hepatic dysfunction } \\
\hline Absent & $\mathbf{0}$ \\
\hline Moderate (diarrhea, N/V, abdominal pain) & 10 \\
\hline Severe (unexplained jaundice) & 20 \\
\hline \multicolumn{2}{|l|}{ Cardiovascular dysfunction } \\
\hline $90-109$ & 5 \\
\hline $110-119$ & 10 \\
\hline $120-129$ & 15 \\
\hline $130-139$ & 20 \\
\hline$\geq 140$ & 25 \\
\hline \multicolumn{2}{|l|}{ Congestive heart failure } \\
\hline Absent & $\mathbf{0}$ \\
\hline Mild (pedal edema) & 5 \\
\hline Moderate (bibasilar rales) & 10 \\
\hline Severe (pulmonary edema) & 15 \\
\hline \multicolumn{2}{|l|}{ Atrial fibrillation } \\
\hline Absent & 0 \\
\hline Present & 10 \\
\hline \multicolumn{2}{|l|}{ Precipitating event } \\
\hline Absent & 0 \\
\hline Present & 10 \\
\hline
\end{tabular}

month after her hospital discharge, she was switched from PTU to methimazole, and the atenolol was discontinued.

\section{Discussion}

Graves' disease is less common in prepubertal than pubertal children [2], and initial presentation with thyroid storm is rare. Infection is a known precipitant of thyroid storm. While medical treatment for RSV is most common in infants,
RSV infection is common in all age groups [3]. However, to the best of our knowledge there are no previous case reports of RSV infection precipitating thyroid storm in prepubertal children. The incidence of pediatric thyrotoxicosis is $0.1 / 100,000$ in young children and $3 / 100,000$ in adolescents $[2,4]$. The majority of cases of pediatric thyrotoxicosis is secondary to Graves' disease, and patients typically present with weight loss, palpitations, tremors, tachycardia, and hypertension [5].

The incidence of thyroid storm is $<10 \%$ of patients hospitalized for thyrotoxicosis, and it is usually associated with a precipitating event, such as infection, surgery, diabetic ketoacidosis, congestive heart failure, pulmonary embolism, toxemia of pregnancy, severe emotional stress, or discontinuation of antithyroid medications [6]. Thyroid storm has been reported after levothyroxine ingestion in a two-yearold patient [7]. Infection is the most common precipitating factor for thyroid storm. Symptoms of thyroid storm include tachycardia, moist skin, fever, agitation, weakness, systolic hypertension, tremor, delirium, palpitations, and altered mental status [8]. Table 2 shows Burch and Wartofsky's criteria for Thyroid Storm in adults, but there are no published criteria specific for pediatric patients. Our patient's scores are highlighted in bold.

Thyroid storm is a severe manifestation of thyrotoxicosis; the mortality rate ranges from 20 to $30 \%$ [6]. Treatment includes correcting the hyperthyroidism with antithyroid medication. Iodine can be used in addition to thioamides to decrease thyroid hormone synthesis. Restoring homoeostasis with IV hydration is essential, and beta-adrenergic blockers may be needed to control the cardiovascular manifestations. Glucocorticoids can be used to block conversion of thyroxine (T4) to triiodothyronine (T3) [2]. It is important to note that PTU is no longer recommended as a first-line agent in either children or adults for the management of Graves' disease due to safety concerns related to liver failure and death in children [9]. However, PTU may be preferable in patients with life-threatening thyrotoxicosis because of its additional inhibition of $\mathrm{T} 4$ to $\mathrm{T} 3$ and in pregnant women due to concerns of methimazole safety to the fetus [10].

\section{Conclusions}

We believe that this patient had underlying, undiagnosed Graves' disease. In addition, the tachypnea, wheezing, Xray findings consistent with viral pneumonia and a positive RSV titer provide strong support for the conclusion that RSV infection triggered her thyroid storm. This case emphasizes the importance of doing a neck exam, including palpation of the thyroid gland, in patients who present with symptoms of respiratory distress and cardiovascular instability; thyrotoxicosis should be part of the differential diagnosis in these cases. A complete clinical history and physical exam are essential for early diagnosis and treatment of this potentially fatal disease.

\section{Conflict of Interests}

The authors declare no conflict of interests. 


\section{References}

[1] H. B. Burch and L. Wartofsky, "Life-threatening thyrotoxicosis: thyroid storm," Endocrinology and Metabolism Clinics of North America, vol. 22, no. 2, pp. 263-277, 1993.

[2] G. Birrell and T. Cheetham, "Juvenile thyrotoxicosis; can we do better?" Archives of Disease in Childhood, vol. 89, no. 8, pp. 745-750, 2004.

[3] M. Wright and G. Piedimonte, "Respiratory syncytial virus prevention and therapy: past, present, and future," Pediatric Pulmonology, vol. 46, pp. 324-347, 2011.

[4] J. Franklyn, "Thyrotoxicosis," Clinical Medicine, vol. 3, no. 1, pp. 11-15, 2003.

[5] M. P. Morrison and A. Schroeder, "Intraoperative identification and management of thyroid storm in children," Otolaryngology, vol. 136, no. 1, pp. 132-133, 2007.

[6] L. Malchiodi, "Thyroid storm," American Journal of Nursing, vol. 102, no. 5, pp. 33-35, 2002.

[7] N. Majlesi, H. A. Greller, M. A. McGuigan, T. Caraccio, M. K. Su, and G. M. Chan, "Thyroid storm after pediatric levothyroxine ingestion," Pediatrics, vol. 126, no. 2, pp. e470e473, 2010.

[8] L. Landgraf, R. Grubina, and J. Chinsky, "Altered mental status in a 16-year-old girl: the calm before the storm," Clinical Pediatrics, vol. 47, no. 7, pp. 720-724, 2008.

[9] S. A. Rivkees and D. R. Mattison, "Ending propylthiouracilinduced liver failure in children," New England Journal of Medicine, vol. 360, no. 15, pp. 1574-1575, 2009.

[10] D. S. Cooper and S. A. Rivkees, "Putting propylthiouracil in perspective," Journal of Clinical Endocrinology and Metabolism, vol. 94, no. 6, pp. 1881-1882, 2009. 